\title{
MONITORING AND PROTECTION OF TIMBER-CONCRETE BRIDGES
}

\author{
Petr Kuklík*， Lukáš Velebil, Anna Gregorová, Petr Svora \\ Czech Technical University in Prague, University Centre for Energy Efficient Buildings, Třinecká 1024, 27343 \\ Buštěhrad, Czech Republic \\ * corresponding author: kuklik@fsv.cvut.cz
}

\begin{abstract}
The majority of timber bridges for ordinary road traffic are often made as timber-concrete composite structures. Concrete slab is something like as umbrella for timber. The reason for problems in timber-concrete bridges is nearly always poor detailing for durability and neglected maintenance. Mainly all aspects of timber protection and maintenance should therefore be considered even during the planning phase of bridge. Paper deals with evaluation of timber properties, system of opto-fiber sensors for monitoring and diagnostics of mechanical stress of timber-concrete bridges, and degradation of timber due to UV radiation, atmospheric conditions and biological agents after application of photocatalytic materials on surface.
\end{abstract}

KEYWORDS: Bridges, concrete, timber, timber-concrete composite, monitoring, durability.

\section{INTRODUCTION}

Timber-concrete composite bridges were first constructed in the United States in the early 20th century. This development was motivated by a shortage of steel that urged builders to use other available structural materials or combinations of such materials [1]. The first reported timber-concrete bridge in the United States dates back to circa 1925. In the 1950s, timberconcrete composite structures started to be applied to bridge construction in other locations, such as Australia and New Zealand. Since the beginning of the 1990s, timber-concrete composite bridges have been increasingly used mainly in some northern and western European countries, such as Finland, Switzerland, France, Germany, and Austria.

From the beginning of applications different systems and configurations have been used for bridges. In general, these can be grouped in two categories, see Fig. 1 .

In the design and performance of timber-concrete composite bridges, a key issue is the connection system, which has a direct influence on both the serviceability limit states and the ultimate limit states.

Bridge structures are normally designed for a long service life, 100 years.

The reason for decay in timber bridges is nearly always poor detailing for durability, low quality of materials applied and neglected maintenance (a regular check of the whole bridge should be made at intervals not exceeding three to five years).

Structural timber as a natural product is part of a life cycle of growing and decomposition. Due to that is also the best to use of either naturally durable or chemically treated timber. Important is also to keep timber constantly dry as is possible.

This paper deals with evaluation of properties of structural timber by semi-destructive method similar
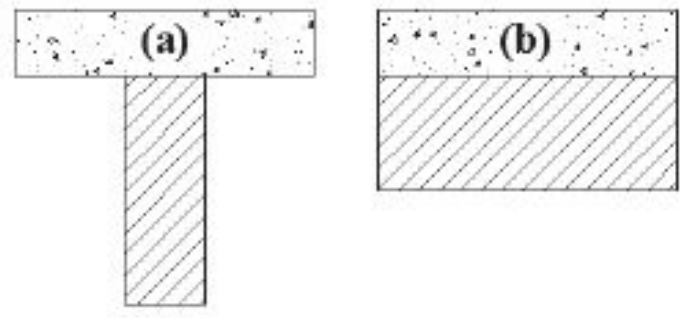

FIgURE 1. Timber-concrete bridge configuration (a) timber beam, (b) timber deck.

to evaluation of concrete, new possibilities of monitoring of bridge structure and new chemical preservation on timber surface.

\section{Evaluation OF DENSity AND MECHANICAL PROPERTIES OF STRUCTURAL TIMBER}

One of the semi-destructive methods of timber evaluation in timber structures is based on measurement of material resistance against penetration of an indenter. The damage of a timber structural member is small after the tests. One of the well-known devices is Pilodyn $6 \mathrm{~J}$ Forest that penetrates the surface layers of timber element by a short pin with the help of an internal spring. It is possible to determine wood density and even the related mechanical properties with the input of the depth of the pin penetration [2].

Wood density is of key importance value of timber. Very important also for the use of non-destructive and semi-destructive methods. Wood density is determined by several factors, e.g. cell diameter and cell wall thickness, proportions of springwood and summerwood, cellulose and lignin content etc. Den- 
sity has a significant influence on wood mechanical properties and the effect of a non-destructive parameter is frequently associated with the density [3]. The depth to which the pin penetrates is indicated on the instrument and is inversely proportional to the wood density.

The equations below can be used for estimation of wood density $\rho_{12}$. The calculations were developed to be used for in situ measurement of timber quality in the existing structures [4] and [5]. They are based on moisture content (MC) measurement, which is an integral part of each testing of wood, and the depth of penetration $t_{p}$.

$$
\begin{gathered}
\rho_{12}=-0.027102 \cdot t_{p, 12}+0.727987 \\
t_{p, 12}=t_{p} \cdot(1-0.007 \cdot \Delta w) \\
\Delta w=w-12
\end{gathered}
$$

where

- $\rho_{12}$ is density of wood with MC of $12 \%\left[\mathrm{~g} \cdot \mathrm{cm}^{-3}\right]$,

- $t_{p, 12}$ the depth of penetration into wood with MC of $12 \%$ [mm],

- $t_{p}$ the depth of penetration into wood with measured $\mathrm{MC}[\mathrm{mm}]$,

- $w$ measured MC [\%].

Not only the strength $f_{m}$, but also the modulus of elasticity $E$ can be estimated with help of penetration depth $t_{p}$ or more precisely density $\rho_{12}$. The relationships between the quantities with specific constants empirically determined resulted from the research [4].

$$
\begin{gathered}
f_{m}=-36.13+0.156743 \cdot \rho_{12} \\
E_{\text {stat }, 05}=-14441.49+55.7834 \cdot \rho_{12}
\end{gathered}
$$

\section{MECHANICAL STRESS MONITORING OF TIMBER-CONCRETE BRIDGES BY FBG SENSORS}

Due to the increasing number of bridge construction faults, there is a need for monitoring their condition, which could reveal the emerging issues in time and warn of imminent violations. One of the innovative methods particularly suitable for long-term continuous monitoring of structural stress is the use of a fiber optic sensor. The technology of Fiber Bragg Grating (FBG) sensor is an optical system used for the same purposes as strain gauge sensors. However, unlike strain gauges, deformation measurements and information transmission are realized by means of light. Energy requirements of the system are therefore reduced and the system is significantly more resistant to most potential sources of interference, including electromagnetic interference. The fiber optic sensor is essentially an optical fiber equipped with a reflecting grid (the so-called Bragg grid), which is produced for example by UV laser firing during fiber production. It is a very small, germanium doped portion of the optical fiber, which in the case of joining this fiber with the stretched body changes its optical properties in a defined manner, and thus it is possible to measure very precisely the elongation of the body. On one fiber can be up to a few tens of independent FBG sensors, each measuring a different place on construction and working at a different wavelength. The fiber is equipped with a cover polymeric sleeve which acts as a fiber protection against moisture and mechanical damage. The FBG sensors are based on a principle of reflection central wavelength of light by the Bragg grid. A part of a supplied signal passes through the grid and a part of the light spectrum is reflected back. In the measuring unit, it is compared to the reference (unloaded) grid tuned to the same wavelength, the deformation is obtained from the difference of values. In the case of a newly made glued laminated timber element, the sensor can be inserted into the wooden structure when it is glued. If an existing or even historical structure is to be monitored, the sensor can be attached to its surface.

The system was tested under laboratory conditions when the fiber with the sensor was embedded into a beam structure of glued laminated timber. The beam was mechanically evaluated by a 4-point loading test until failure, see Fig. 2a). The correct function of the sensor was examined and a obtained data were compared with an analytical approach, see Fig. 2b). More detailed information about experiments and achieved results can be found in [6].

Absolute error of measurement compared to analytical calculation is to $10 \%$. From the comparison of the measured and calculated data it can be stated that the FBG sensors are also suitable for application to timber elements, for example for monitoring the stress of timber-concrete bridge structures. The system can be configured to track the behaviour of the load bearing element during the lifetime of the structure and if necessary, alert to structural overload or technical problems. The technology of fiber optic sensors could be one of the ways to control the state of the bridges in the future.

\section{Protection of timber By PHOTOCATALYTIC MATERIALS}

Generally timber protection materials should prolong lifetime of timber elements. The main role of the group protective materials based on photocatalysis is to protect timber element before color changing, moulds and fungus. The most spread photocatalytic materials for wood protection are $\mathrm{TiO}_{2}, \mathrm{ZnO}, \mathrm{CeO}_{2}$ [7] and $\mathrm{WO}_{3}$. They are used in nano-form and usually applied as a transparent coating. There are two ways, particle can be directly mixed with the solution or encapsulated into porous, resistant material (e.g. silicates) and then apply on the timber. Encapsulation 


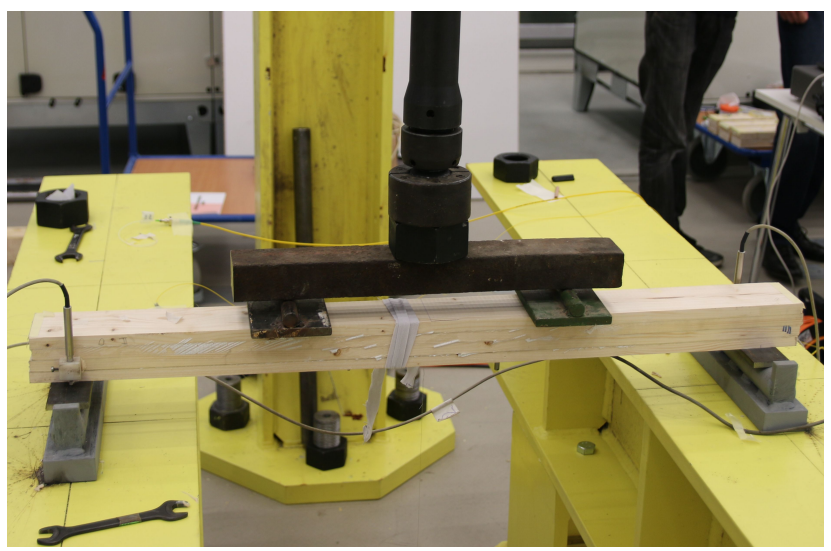

(A).

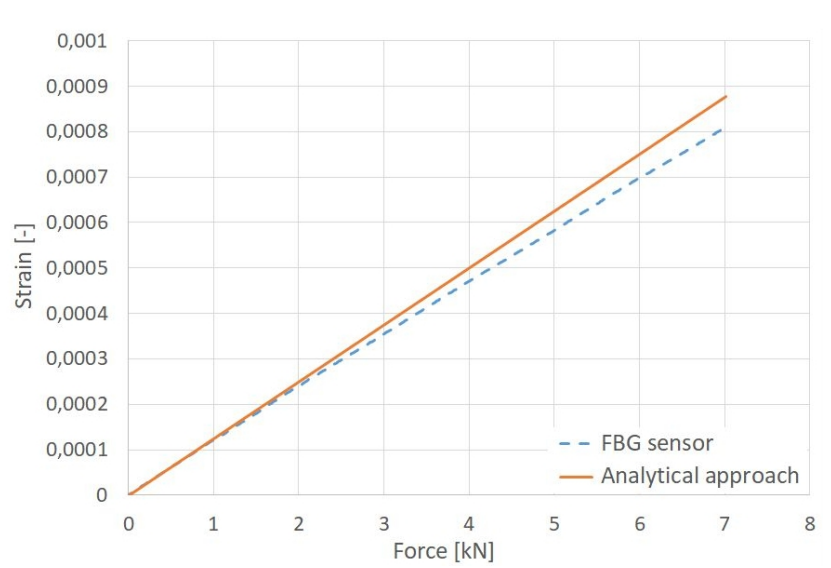

(B).

FiguRE 2. Laboratory testing of FBG sensors a) experimental arrangement of the test; b) comparison of measured and calculated data.

should avoid damage of timber and save ability to decompose organic compound.

Nowadays is tendency made more efficient photocatalytic materials by dopping. Dopping should caused decreasing band gap between valence band and conductive band which means that absorption expand in the visible region of light. Until now the results in this research area are not satisfactory. Dopped photocatalytic material are not such efficient like un-dopped one.

Less known is using of iron oxides. They are used in cases when it is not necessary keep wood color.

Other inorganic compound which were studied as a photocatalyzer were $\mathrm{CdS}, \mathrm{CuO}, \mathrm{MoO}_{3}, \mathrm{Cr}_{2} \mathrm{O}_{3}$, but they are not used in bid scale.

$\mathrm{TiO}_{2}$ belong to the most known materials with the photocatalytic properties. It is mainly designed for decomposition of organic compound.

A lot of materials with the photocatalytic properties were used earlier as a pigments or part of compound created pigments. It was observed that some of them, react with surroundings. Exterior paints based on titania had tend to chalking which means that in surface stayed non-adhesive powder. $\mathrm{TiO}_{2}$ is present in lot of minerals which were known already in ancient times but $\mathrm{TiO}_{2}$ itself as a compound is known from nineteenth century. On the beginning of the twentieth century start industrial production. Timber protection with $\mathrm{TiO}_{2}$.

$\mathrm{TiO}_{2}$ was tested in different type of wood species different climatic conditions. The use of $\mathrm{TiO}_{2}$ usually increased resistance against the fungi and mould. On the other hand it was mentioned in some works the use of $\mathrm{TiO}_{2}$ negatively influenced mechanical properties.

The morphology of $\mathrm{TiO}_{2}$ is varied from spheres particle to tubes. In our focus is planar particles-leaflets of $\mathrm{TiO}_{2}$. The type what we use is possible prepare as a photoactive and also as a non-photoactive.

The synthesis of $\mathrm{TiO}_{2}$ is simple but time consumed.

The starting compounds are titanium sulphate nhydrate which is dissolved in deionized water. Next step is precipitation by concentrated aqueous $\mathrm{NH}_{3}$. White precipitate is filtered, properly washed and transferred into a beaker and re-suspended in deionized water. After that is added $\mathrm{H}_{2} \mathrm{O}_{2}$ until solution became yellow. Last step is lyophilisation. More details about synthesis is refer in literature [8]. We are also looking for the ways how to make it shorter and keep the morphology and same physico-chemical properties.

The goal of our work is study interaction between planar particles of $\mathrm{TiO}_{2}$ and wood matter. Testing is running on the pine wood and beech wood. The samples were coated with different coating and concentrations of $\mathrm{TiO}_{2}$.

Experimental data from UV-VIS spectroscopy clearly show that the planar particle of $\mathrm{TiO}_{2}$ absorbed wide range of UV light (UVA, UVB) (Fig. 3). $\mathrm{TiO}_{2}$ was annealed on $200^{\circ} \mathrm{C}, 250^{\circ} \mathrm{C}$ and $300^{\circ} \mathrm{C}$ due to remove residual peroxide after the lyophilisation. Also we want to know whether the annealing temperature has an impact on the absorption of UV-light. TiO2 annealed on $200^{\circ} \mathrm{C}$ and $300^{\circ} \mathrm{C}$ have the maximum on the same wave length $(310 \mathrm{~nm})$, maximum $\mathrm{TiO}_{2}$ annealed on $250^{\circ} \mathrm{C}$ is slightly shifted $(320 \mathrm{~nm})$. Shape and maximum of the absorbance's curves is in all cases similar. On the base of experimental data we assumed that in temperature range between $200^{\circ} \mathrm{C}$ and $300^{\circ} \mathrm{C}$ absorbance is same.

The planar morphology was proved by electron microscopy (Fig. 4). The surface of the particle is not plain but wavy and also it is not completely continuous. The holes cover $20 \%$ of the surface and aggregates $10 \%$. Holes and aggregates in this amount have no negative impact on the UV absorption of the material as was proven by UV-VIS spectroscopy.

\section{Summary}

- Timber-concrete composite bridges are a technical solution with great potential for bridge construction. The wide range of examples also prove that this 


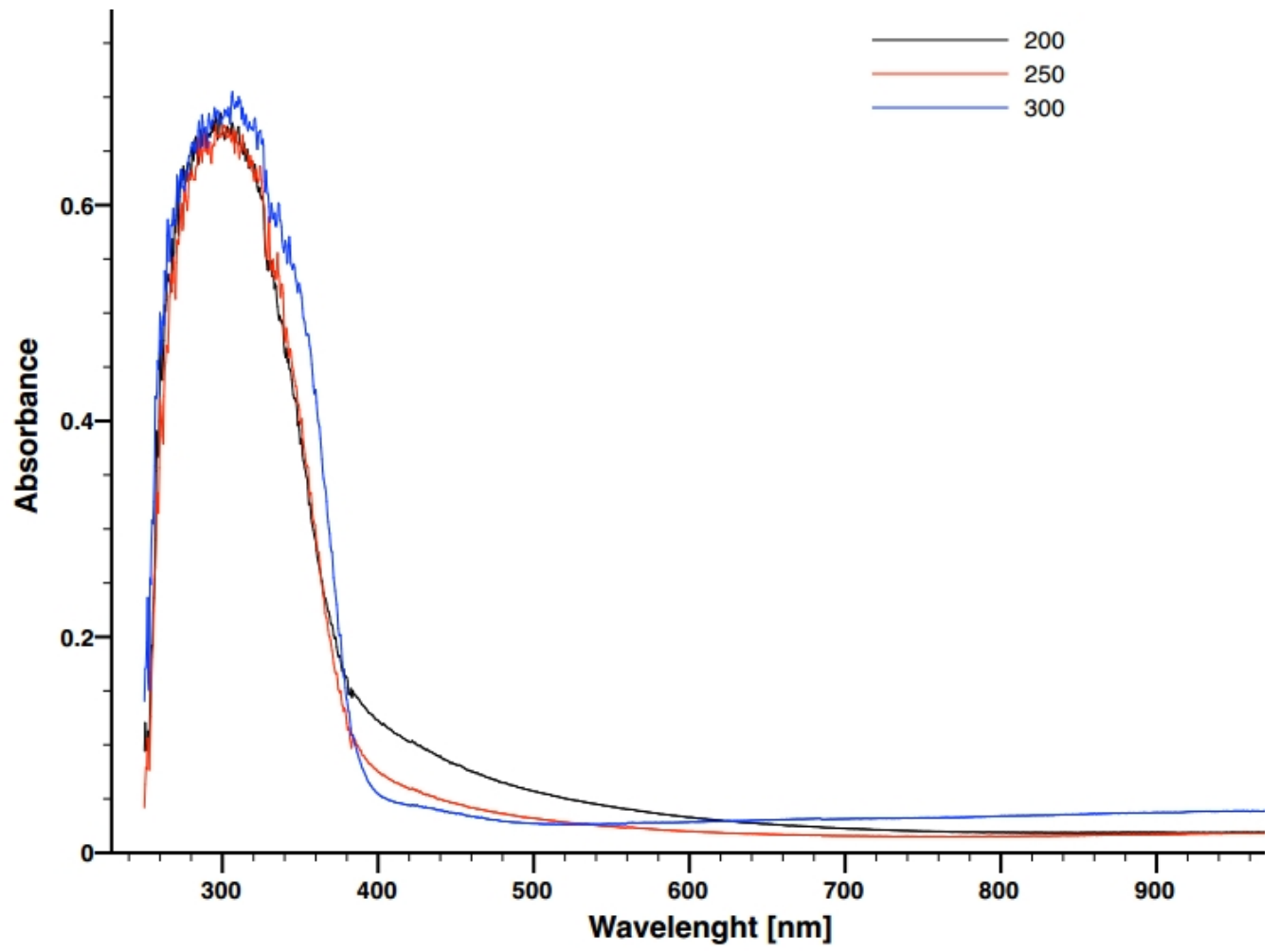

Figure 3. UV-VIS of planar, amorphous $\mathrm{TiO}_{2}$.

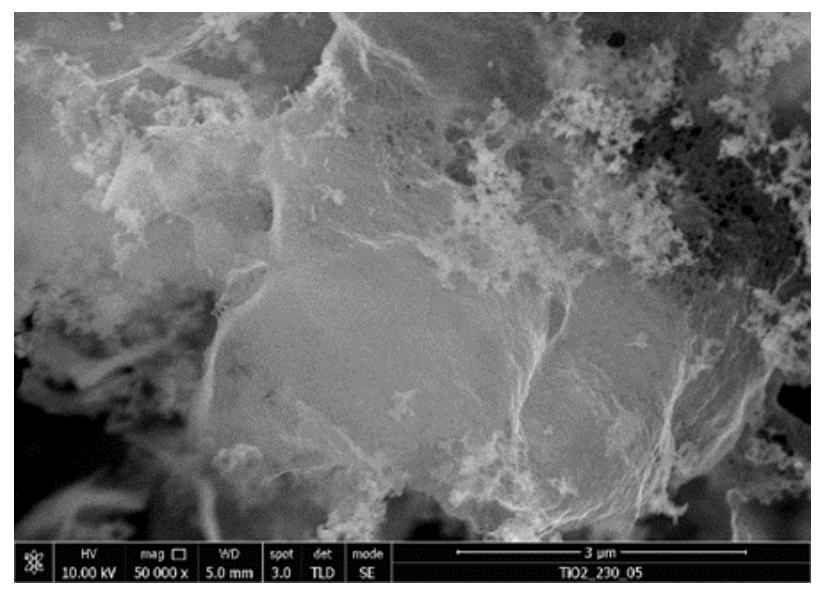

FiguRE 4. UHRSEM - Planar particle of amorphous $\mathrm{TiO}_{2}$.

technology very useful in the past but also has enormous potential for use in the future.

- Several aspects for future application of nondestructive techniques in bridge survey and restoration shall be considered. This may include enhancement of non-destructive methods accounting for specific applications in the structural assessment of existing bridges and preparation of draft proposals for technical guidelines in the field of bridges inspection.

- The idea protect external timber construction with the photocatalytic material is not new. What is missing are information's about the interaction be- tween photocatalytic material and timber. We chose as a model material planar $\mathrm{TiO}_{2}$ because it is possible prepare it in two forms amorphous (non-photoactive) and crystalline (photoactive). We can study interaction of two phases morphologically identical material which is very important because research community admit theory where the morphology is one of the main factor with big impact on the photocatalytic properties. We are able also study role of the coating solvent (water, water glass, acryl). In case of water solution we assume that water evaporate and the particles are bonded by Van der Waals force so we will study directly interaction particle - wood, in case of water glass solution the inorganic porous structure is created and particles are surrounded silicate chains (system to study particle - silicate chain - wood) and in case of acrylic solution the organic porous structure is created (system to study particle - acrylic acid compounds). Obtain data will be used for new evaluation method of influence photocatalytic materials on surface of timber structures, mainly timber bridges.

\section{ACKNOWLEDGEMENTS}

This work is supported by the project GA18-26297S "Study of interactions in system: wooden surface - amorphus layer of TiO2 - crystalline layer TiO2".

\section{REFERENCES}

[1] J. P. Wacker, A. Dias, T. K. Hosteng. Investigation of early timber-concrete composite bridges in the united 
states. In Proceedings, ICTB 2017, 3rd international conference on timber bridges, p. 11. Skellefteå, Sweden, 2017.

[2] H. Hasníková, P. Kuklík. Various non-destructive methods for investigation of timber members from a historical structure. Wood research 59(03):411-420, 2014 .

[3] B. Kasal, R. Anthony. Advances in in situ evaluation of timber structures. Progress in Structural Engineering and Materials 6:94 - 103, 2004. DOI:10.1002/pse.170

[4] A. Kuklíková. Kompozitní dřevobetonové konstrukce. Ph.D. thesis, Czech Technical University in Prague, Faculty of Civil Engineering, Prague, 2004. In Czech.

[5] J. Maddox, P. Kuklík. Non-destructive testing methods for determining material characteristis values of historic timber structures. In M. C. Forde (ed.), Structural Faults 8 Repair - 2016. 16th International Conference and Exhibition. Edinburgh, 17.05.2016 19.05.2016. Engineering Technics Press Edinburgh, 2016.
[6] L. Velebil, R. Zelený, J. Včelák, et al. Optical fibre sensors as a potential solution for monitoring wooden structures. In WCTE 2016 CD-ROM Proceedings. Vienna, 2016.

[7] M. Nikolic, J. Lawther, A. Sanadi. Use of nanofillers in wood coatings: a scientific review. Journal of Coatings Technology and Research 12:445-461, 2015. DOI:10.1007/s11998-015-9659-2

[8] J. Šubrt, P. Pulišová, J. Boháček, et al. Highly photoactive $2 \mathrm{~d}$ titanium dioxide nanostructures prepared from lyophilized aqueous colloids of peroxopolytitanic acid. Materials Research Bulletin 49:405412, 2014. DOI:10.1016/j.materresbull.2013.09.028 